\title{
The Research of Impact Factors Residents Buying New Energy Vehicles
}

\author{
Jiangping Li \\ School of Economics, Shanghai University, Shanghai, China \\ Email address: \\ lijiangping1818@163.com
}

\section{To cite this article:}

Jiangping Li. The Research of Impact Factors Residents Buying New Energy Vehicles. International Journal of Energy and Power Engineering. Vol. 4, No. 5, 2015, pp. 298-303. doi: 10.11648/j.ijepe.20150405.19

\begin{abstract}
New energy vehicles are the development trend of automobile industry in the future. At present, new energy vehicles are in the embarrassing situation that people who support the new energy vehicles do not buy them. Existing researches on the behavior of consumers to purchase new energy vehicles are mainly studying in the market environment and preferential policies on the macro level. The micro level of individual consumers in China about new energy vehicles is blank. Through three ingredients attitude model to design the questionnaire, there are 1200 questionnaires are collected in major driving and field distributed in the center of Shanghai. 1131 questionnaires were effective. The SPSS20.0 software is used to calculate principal component analysis to extract the six impact factors on the consumer purchase of new energy car. There are quality factor, environmental perception influence factor, quality factor, battery car cost impact factors, reference group influence factor and subsidy policy influence factor, respectively. Results show that residents have higher purchase intention $(65 \%)$ on new energy vehicles. But only $5 \%$ of the people affected by above six factors would buy new energy vehicles. Based on the questionnaire results, we provide some constructive suggestions with Chinese government and enterprises aspects to solve the embarrassing situation.
\end{abstract}

Keywords: New Energy Vehicles, Purchase Decision, Influence Factor, Principal Component Analysis, Factorial Analysis

\section{居民购买新能源汽车的影响因素实证研究}

\author{
黎江平 \\ 经济学院, 上海大学, 上海, 中国

\section{邮箱} \\ 1ijiangping1818@163.com
}

\begin{abstract}
摘要: 新能源汽车是未来汽车工业发展的趋势, 目前中国市场上的新能源汽车确是处于叫好不叫座的尴尬处境。中国 已有研究对消费者购买新能源汽车行为的相关问题主要是在市场环境和优惠政策等宏观层面进行了研究, 而缺乏关于 消费者个人的微观层面的实证研究。笔者通过三成份态度模型设计问卷, 在中国上海市各大驾校和市中心人群聚集区 实地发放 1200 份问卷，共获得有效问卷1131份。然后运用 $\operatorname{sps} 20.0$ 软件采用主成分分析法，提取出 6 个居民购买新能源 汽车的影响因子，分别为汽车本身品质因子、电池品质因子、环保感知影响因子、汽车成本影响因子、参考群体影响 因子和补贴政策影响因子。问卷显示居民对新能源汽车有较高的购买意愿 (65\%) 但受上述6个影响因子的影响确只有 5\%的人产生了购买行为, 通过对问卷结果总结, 实证分析的基础上在论文最后从中国政府和企业两个方面对解决新能 源汽车叫好不叫座的处境提供了一些建设性建议。
\end{abstract}

关键词: 新能源汽车, 购买决策, 影响因素, 主成分分析法, 因子分析 


\section{1. 引言}

随着全球石油能源的日益枯竭和环境污染的日益严 重, 全球的能源使用和环境问题面临着日益严峻的巨大挑 战。而在现代化城市中, 汽车是石油消耗和二氧化碳排放 的大户, 现今中国已是世界上第一大汽车生产国和消费国, 汽车的大量使用给我们带来便捷的同时也带来了巨大的 能源挑战和环境问题。早在2009年1月，中国国家政府就 出台《汽车产业调整振兴规划》 ${ }^{1}$, 将发展新能源汽车提 到了前所未有的高度。新能源汽车将是未来汽车工业的发 展趋势, 以混合动力汽车为短期目标, 纯电动汽车为长期 发展方向, 首先占领城市公共服务领域, 然后一步一步向 家庭使用推广 ${ }^{[1]}$ 。目前中国国内已有君越的混合动力车、 比亚迪系纯电动汽车、奇瑞纯电动汽车等进入线下量产阶 段，但市场销售均不理想。对于如何解决现阶段新能源汽 车叫好不叫座的窘境, 中国国内已有研究主要从市场环境 和优惠政策等宏观层面对消费者购买新能源汽车行为进 行了研究, 而缺乏对消费者个人微观层面的购买意愿和购 买决策影响因素的实证研究。因此, 本文基于此问题, 选 择了中国消费能力最高、新能源汽车购买配套制度更加完 善、新能源汽车保有量居于全国前列的上海市作为研究对 象, 对城市居民购买新能源汽车的决策影响因素进行实证 分析, 然后对症下药, 以期能够对扶持中国新能源工业的 发展提供科学依据。

\section{2. 问卷调查过程与信度检验}

\section{1. 问卷设计}

本文通过研究中国国内外消费者行为的相关文献, 消 费者行为的产生应当从消费者开始认知这个产品, 产品知 识的认知是了解一个产品最基本的过程; 由认知到产生态 度到产生行为, 这个过程比较复杂, 我们根据三成份态度 模型 [2], 认为态度主要由认知、情感、和行为倾向这三 因素构成。认知因素是指消费者对态度标的物的所有经验 和信息集合而成的知识与信念。情感因素是指消费者对态 度标的物所产生的正面或负面的感觉。行为倾向是指消费 者对态度标的物所可能产生特定行为倾向和可能性。

本问卷正是基于这态度的三成份模型来进行设计，大 致将从四个大方面来研究消费者购买行为的影响因素, 分 别为个人因素、社会因素、产品因素和政策因素四个方面 总共 22 个重要问题题项, 再加上基本信息收集条目组成本 问卷。笔者采用Likert五级分量表 [3], 将22个重要题项 划分为非常不赞同、不赞同、一般、赞同、非常赞同五个 量级, 分值为 1 分到 5 分。

\section{2. 调查对象和问卷发放}

1 中国国务院2009年1月推出的振兴汽车产业五大规划, 主要内容为培育 汽车消费市场、推进汽车产业重组、支持企业技术改造、实施新能源汽 车战略、支持汽车生产企业发展自主品牌等五大方面
作者选取中国上海市各区各大汽车驾校、市区各大购 物中心、高档写字楼聚集区、居民区等地方为调查地点, 主要目的在于寻找有购买能力, 对新事物比较容易接受的 中青年白领、社会精英这类人。主要采用实地拦截式的自 愿调查或委托亲戚朋友在他们上班楼里面发放问卷。总共 发放1200份问卷，回收1131份问卷。

\section{3. 问卷信度检验}

本文采用SPSS20.0对所有的1131份问卷进行了总体 信度检验, 其Cronbach a 信度系数为 0.857 , 说明本问卷 整体具有很高的可信度。所以, 本问卷调查所得到的数据 是可信的, 基于问卷数据进行的数据分析结果也是可信的。 另外, 判断样本充足性的检验系数 (Kai ser-Meyer-01kin) 为 0.867 , 远大于 0.5 的经验值, 样本充足性好; Bartlett 的球形检验近似卡方值为 9474.332 , 自由度为 231 , 显著 性为 0.000 , 拒绝零假设, 说明适合因子分析。

表一 KMO和Bartlett的检验。

\begin{tabular}{lll}
\hline 取样足够度的 Kaiser-Meyer-01kin 度量。 & .867 \\
\hline \multirow{3}{*}{ Bartlett 的球形度检验 } & 近似卡方 & df \\
& Sig. & 23174.332 \\
& & .000 \\
\hline
\end{tabular}

\section{3. 实证结果分析}

\section{1. 样本个性特征的描述性统计分析}

在回收的1131份问卷中有 1126 份填写了性别, 其中, 男性686位, 女性437位, 分别占比 $61 \%$ 和 $39 \%$ 。新能源汽车 的购车意愿与购车比例如下表二。其中， $4.9 \%$ 的人购买过 新能源汽车, $95.1 \%$ 的人未曾购买过。但有 $65.1 \%$ 的人接受 调查时明确表示购车时会考虑购买新能源汽车，34.9\%的 人不愿意购买。这充分说明新能源汽车的潜在市场是巨大 的, 并且城市居民对新能源汽车有相当程度的了解, 这也 一定程度上保障了调查结果的可信性。但只有 $5 \%$ 的人购买 过新能源汽车, 为什么有购买意愿的人群和实施购买行为 的人群占比差距如此之大, 影响其决策行为的影响因素有 哪些? 那么研究消费者购车行为的决策影响因素是很有 必要的。

表二 新能源汽车购买意愿统计表。

\begin{tabular}{lllll}
\hline & & 频率 & 有效百分比 & 问卷缺失/总数 \\
\hline 是否购买过新能 & 是 & 55 & $4.9 \%$ & \multirow{2}{*}{$12 / 1131$} \\
源汽车 & 否 & 1064 & $95.1 \%$ & \\
购车时是否会考 & 是 & 728 & $65.1 \%$ & $13 / 1131$ \\
虑新能源汽车 & 否 & 390 & $34.9 \%$ & \\
\hline
\end{tabular}

\section{2. 决策影响变量的选择和特征分析}

通过阅读相关文献, 本文对消费者的行为研究主要是 基于消费者购买决策行为理论, 主要将消费者购买决策因 素分为内部因素和外部因素 [4]-[10]。内因主要是指消费 者自身的影响因素, 如个人生活经历、需求、收入、观念 
等等; 外因主要是指对消费者购买产生外部影响的因素, 包括参照群体 (朋友亲人) 的影响、产品质量、政府政策 因素的影响等等。将内外因结合我们设计出如下表三的 22 影响因素变量:（）内数字表示题项个数。

表三 购买决策影响因素。

\begin{tabular}{ll}
\hline 内部因素 & 外部因素 \\
\hline 1、消费者个人素质下的消费观念 (1) & 1、产品本身的影响因素 (9) \\
2、消费者收入、年龄等特征 (基本 & 2、社会参照群体的影响 $(3)$ \\
信息收集栏内, 不在22题项中) & 3、政策影响因素 (2) \\
3、消费者对新能源汽车的形象感知 & 4、售前售后服务 (3) \\
(2) & 5、新能源汽车电池的影响 (2) \\
\hline
\end{tabular}

通过对调查问卷的 22 题项采用Likert五级分量打分 的均值统计分析, 得到表四 (全部题项都是: $x \times x$ 对我选 择新能源汽车很重要, 表中只列出×x×这个条件, 后面的
“对我选择新能源汽车很重要” 都考虑到表格容量省略不 写）, 从表中我们可以看出, 除了最后一项略低于3分, 其他均值均大于 3 分。说明我们调查题项所列影响因素是 消费者购买决策中考虑的因素。其中, 新能源汽车电池的 续航里程和充电时间、寿命得分均值分别高达4. 34、4.33, 分列第 $1 、 2$ 位。说明大家购买新能源汽车首要考虑的是汽 车电池问题。然后得分排名前列的有售后服务、汽车安全 问题、绿色消费观念、汽车本身品质因素等等。排名末尾 的有购买补贴额度的了解程度、参照群体的影响和消费者 对新能源汽车的形象感知。说明大家对国家的新能源汽车 补贴政策不够了解, 这是政府和企业应该大力宣传的地方; 另一个说明消费者购车行为受参照群体和新能源汽车形 象感知影响相对较低。

表四 影响因素的变量选择条项和均值特征。

\begin{tabular}{|c|c|c|c|c|c|}
\hline 条项 & 均值 & 标准差 & 条项 & 均值 & 标准差 \\
\hline 一次充电可行驶路程 & 4.34 & 0.734 & 专业售前咨询 & 3.86 & 0.825 \\
\hline 电池充电时间和使用寿命 & 4. 33 & 0.749 & 汽车销售价格 & 3.86 & 0.860 \\
\hline 良好的售后服务 & 4. 2 & 0.792 & 便捷的购车信贷服务 & 3.75 & 0.901 \\
\hline 汽车安全装备 & 4. 18 & 0.772 & 汽车造型 & 3.67 & 0.866 \\
\hline 我们的消费应对环境负责 & 4. 01 & 0.815 & 驾驶新能源汽车是一种环保主义者 & 3.55 & 0.959 \\
\hline 汽车内部空间 & 4. 00 & 0.773 & 驾驶新能源汽车是一种关心社会的人 & 3.48 & 0.948 \\
\hline 消费者口碑 & 3.99 & 0.794 & 购买新能源汽车受家人影响 & 3.32 & 0.912 \\
\hline 汽车能耗费用 & 3.96 & 0.815 & 购买新能源汽车受到同事偏好影响 & 3.07 & 0.919 \\
\hline 汽车维修和零部件费用 & 3.92 & 0.838 & 我很满意国家和上海对新能源汽车的购买补贴额度 & 3. 01 & 0.839 \\
\hline 汽车车身结构设计 & 3.9 & 0.823 & 我很了解国家和上海对新能源汽车的购买补贴额度 & 2. 89 & 0.884 \\
\hline
\end{tabular}

\section{4. 新能源汽车购买决策影响因素的因子分析}

从上文中的问卷信度检验Kai ser-Meyer-01kin检验和Bartlett的球形检验：KM0值大于 0.5 , Bartlett的球形检验 拒绝零假设, 说明相关矩阵不是单位阵, 本问卷数据适合进行因子分析。利用主成分分析法提取因子得到结果如表五:

表五 影响因素对居民新能源汽车购买决策的方差贡献率（解释总方差）。

\begin{tabular}{|c|c|c|c|c|c|c|}
\hline \multirow{2}{*}{$\begin{array}{l}\text { 因子 } \\
\text { component }\end{array}$} & \multicolumn{3}{|c|}{ 初始特征值 Initial Eigenvalues } & \multicolumn{3}{|c|}{ 提取平方和载入 Extraction Sums of Squared Loadings } \\
\hline & 特征值 & 方差贡献率 (\%) & 累计贡献率 (\%) & 特征值 & 方差贡献率（\%） & 累计贡献率 (\%) \\
\hline 1 & 6.592 & 29.964 & 29.964 & 6.592 & 29.964 & 29.964 \\
\hline 2 & 2. 034 & 9. 243 & 39. 207 & 2.034 & 9. 243 & 39. 207 \\
\hline 3 & 1.685 & 7. 659 & 46.866 & 1. 685 & 7. 659 & 46. 866 \\
\hline 4 & 1.41 & 6. 411 & 53.278 & 1.41 & 6. 411 & 53.278 \\
\hline 5 & 1.244 & 5.654 & 58.931 & 1.244 & 5.654 & 58.931 \\
\hline 6 & 1. 118 & 5. 083 & 64.014 & 1. 118 & 5. 083 & 64.014 \\
\hline 7 & 0.925 & 4. 204 & 68.219 & & & \\
\hline 8 & 0.812 & 3. 692 & 71.911 & & & \\
\hline 9 & 0.72 & 3. 272 & 75. 182 & & & \\
\hline 10 & 0.642 & 2. 916 & 78. 099 & & & \\
\hline 11 & 0.616 & 2.8 & 80.898 & & & \\
\hline 12 & 0.551 & 2. 506 & 83.405 & & & \\
\hline 13 & 0.473 & 2.15 & 85.554 & & & \\
\hline 14 & 0.461 & 2. 098 & 87.652 & & & \\
\hline 15 & 0.445 & 2. 024 & 89. 676 & & & \\
\hline 16 & 0.412 & 1. 873 & 91.55 & & & \\
\hline 17 & 0.381 & 1. 733 & 93.283 & & & \\
\hline 18 & 0.373 & 1.693 & 94.976 & & & \\
\hline 19 & 0.354 & 1. 61 & 96.586 & & & \\
\hline 20 & 0.321 & 1. 457 & 98.043 & & & \\
\hline 21 & 0.244 & 1.11 & 99.153 & & & \\
\hline 22 & 0.186 & 0.847 & 100 & & & \\
\hline
\end{tabular}


通过上表可以看出, 根据特征值大于 1 的理论特点, 我们提取前 6 个因子, 前 6 个因子对整体 22 个所有因素的累积贡 献率达到了 $64.014 \%$, 说明前六个因子占整体 22 个因素的影响量巨大, 效果显著, 可以充分反映出原始所有因素包含的 信息。

计算旋转后的因子载荷结果如表六 (表六中全部题项都是: $x \times x$ 对我选择新能源汽车很重要, 表中只列出 $x \times x$ 这个 条件）所示，我们根据此表可以得出各个因子的表达式，此表只显示因素的影响系数大于 0.6 的值:

表六 旋转后居民购买新能源汽车的影响因素的因子载荷（旋转成份矩阵）。

\begin{tabular}{|c|c|c|c|c|c|c|}
\hline \multirow{2}{*}{ 条目 } & \multicolumn{6}{|l|}{ 主因子 } \\
\hline & 1 & 2 & 3 & 4 & 5 & 6 \\
\hline 汽车内部空间 & 0.752 & 0.18 & 0.192 & 0.018 & 0.076 & -0.046 \\
\hline 汽车噪声 & 0.74 & 0.131 & 0.159 & -0.021 & 0.173 & -0.007 \\
\hline 汽车车身结构设计 & 0.669 & 0.146 & 0.144 & 0.05 & 0.095 & 0.06 \\
\hline 汽车造型 & 0.633 & 0.125 & 0.08 & 0.163 & 0.012 & 0.033 \\
\hline 汽车安全装备 & 0.623 & 0.16 & 0.124 & 0.182 & 0.097 & 0.094 \\
\hline 专业售前咨询 & 0.605 & 0.378 & 0.296 & -0.035 & 0.137 & 0.015 \\
\hline 便捷的购车信贷服务 & 0.567 & 0.098 & 0.034 & 0.222 & 0.166 & 0.064 \\
\hline 消费者口碑 & 0.482 & 0.46 & 0.219 & 0.084 & 0.104 & 0.131 \\
\hline 电池充电时间和使用寿命 & 0.248 & 0.815 & 0.164 & 0.049 & 0.094 & 0.003 \\
\hline 一次充电可以行驶的路程 & 0.183 & 0.782 & 0.116 & 0.153 & 0.044 & 0.014 \\
\hline 良好的售后服务 & 0.32 & 0.767 & 0.146 & 0.077 & 0.092 & 0.012 \\
\hline 驾驶新能源汽车的人是环保主义者 & 0.205 & 0.155 & 0.888 & 0.01 & 0.136 & 0.018 \\
\hline 驾驶新能源汽车的人是关心社会的人 & 0.198 & 0.192 & 0.843 & -0.04 & 0.115 & 0.02 \\
\hline 我们的消费应当对环境负责 & 0.299 & 0.136 & 0.787 & 0.061 & 0.031 & 0.088 \\
\hline 汽车维修和零部件费用 & 0.142 & 0.05 & -0.027 & 0.867 & 0.086 & -0.017 \\
\hline 汽车销售价格 & 0.147 & -0.005 & 0.006 & 0.836 & 0.119 & 0.065 \\
\hline 汽车能耗费用 & 0.087 & 0.208 & 0.04 & 0.732 & 0.089 & 0.014 \\
\hline 购买新能源汽车会受到交往的人际关系网影响 & 0.115 & 0.055 & 0.048 & 0.128 & 0.885 & 0.098 \\
\hline 购买新能源汽车会受到家人的影响 & 0.14 & 0.029 & 0.063 & 0.212 & 0.842 & 0.074 \\
\hline 购买新能源汽车会受到同事的影响 & 0.249 & 0.175 & 0.173 & -0.009 & 0.677 & 0.031 \\
\hline 我很了解国家和上海目前对新能源汽车的补贴额度 & 0.061 & 0.052 & 0.03 & 0.01 & 0.006 & 0.893 \\
\hline 我很满意国家和上海目前对新能源汽车的补贴额度 & 0.072 & -0.005 & 0.063 & 0.045 & 0.17 & 0.863 \\
\hline
\end{tabular}

在第一个因子中，有汽车内部空间、汽车噪声、汽车 车身结构设计、汽车造型、汽车安全装备、专业售前咨询 这六个因素的系数较大, 其调查的得分均值分别为 $4 、 3.97$ 、 $3.9 、 3.67 、 4.18 、 3.86$. 从均值得分我们就可以看出, 消 费者对新能源汽车的安全装备和汽车内部空间要求特别 高, 也从一定侧面体现出质量工艺更好的、更安全的外国 车和空间大且舒适的SUV目前在中国国内整车市场的畅销 是有原因的, 也进一步证明我们调研数据的可信性。我们 把其中得分排名前五的因素都归结为汽车本身的质量、设 计、安全等相关因素, 第六个因素专业售前咨询得分不高, 相对前面几个是消费者更不受重视的因素, 所以笔者总结 这六个因素为居民购买新能源汽车的 “汽车本身品质因 子”。

第二个因子中, 有电池充电时间和使用寿命、一次充 电可以行使的路程和良好的售后服务这三个因素, 其调查 得分均值分别为 $4.33 、 4.34 、 4.20$. 得分均值是 22 个因素 中排行最高的 3 个, 说明这三个因素是消费者最看重的, 对消费者购买新能源汽车影响最大的三个决策因素。我们 把这个归为 “电池与售后服务因子”。这个售后服务中, 我们在调查过程中也了解到消费者对售后服务中新能源 汽车的电池维修保养与更换是最关心的。所以从大方向来 概括的话这个因子可以归结为 “电池品质因子”。
第三个因子中, 有驾驶新能源汽车的人是一种环保主 义者的人, 驾驶新能源汽车的人是一种关心社会的人, 我 认为我们的消费应该对环境负责这三个因素, 其调查得分 均值分别为 $3.55 、 3.48 、 4.01$. 其中消费应该对环境负责 这个因素得分较高, 我们在调查过程中也询问过受访者, 他们是否觉得开新能源汽车的人是一种环保主义者, 他们 给出的答案是不确定, 但问到他们自己是否会进行绿色消 费, 自己会不会积极参与到绿色消费当中, $80 \%$ 以上的消 费者都说一定会的! 说明居民消费时候不确定其他人消费 是否是环保主义者, 他们受其他人的消费影响程度不确定, 但他们自己本身是愿意进行绿色消费的, 自身的绿色消费 观就对他们的消费产生了重大影响。所以绿色的环保观和 环保形象感知对消费者购买新能源汽车有较为显著影响。 我们将这个因子定为 “环保感知影响因子”。

第四个因子中, 有汽车维修和零部件费用、汽车销售 价格、汽车能耗费用这三个因素, 其调查得分均值分别为 3. 92、3. 86、3. 96. 调查显示消费者对新能源汽车的销售 价格比同档次的传统车高 3 万以内, 是可以接受的! 但如果 日均使用成本只要比传统车要高, 他们购买意愿就下降了 一半以上。所以新能源汽车的使用成本比销售成本更受大 家看重。总体上可以把这个使用成本和销售成本归结为 “汽车成本因子”。 
第五个因子中, 有购买新能源汽车会受到人际关系网 的影响, 受到家人的影响, 受到同事们偏好的影响这三个 因素，其调查得分均值分别为 $3.08 、 3.32 、 3.07$. 我们可 以看出这三者对个人购买新能源汽车的影响程度一般。这 个因子中, 主要是考量居民购买新能源汽车受身边的参照 群体 (亲人、朋友、同事) 的影响程度。我们把它定为 “参 照群体影响因子”。

第六个因子中, 有我很了解国家和上海目前对新能源 汽车的购买补贴额度, 我很满意国家和上海目前对新能源 汽车的购买补贴额度这两个因素, 其调查得分分别为 2.89 、 3. 01. 得分都比较低, 说明补贴政策对居民购买新能源汽 车影响程度一般, 居民对上海市的新能源补贴政策并没有 产生很高的热情。我们把这个影响因子定为 “补贴政策影 响因子”。

\section{5. 研究结论与对策建议}

\section{1. 研究结论}

(1) 从大家对新能源汽车的了解程度来看, 不了解、 不太了解、一般、比较了解、十分了解这 5 个量级占比分 别为 $4.1 \% 、 20 \% 、 51 \% 、 21.2 \% 、 3.7 \%$ 。有高达 $51 \%$ 的人选择 了解程度一般, 另有 $20 \%$ 的人选择不太了解。说明大部分 居民对新能源汽车的了解程度并不高, 或者只是听过这个 概念, 但具体情况并不清楚, 这就很容易从一个方面解释 新能源汽车叫好不叫座的原因, 大家都不太了解, 怎么产 生购买行为。

（2）从购买决策的主要影响因素来看, 主要因素包 括上面调查项目中的 22 条项。我们根据主成分分析法将其 划分为汽车本身品质因子、电池品质因子、环保感知影响 因子、汽车成本因子、参照群体影响因子和补贴政策影响 因子。六个影响因子在新能源汽车购买决策中共计贡献 64. $014 \%$ 。

（3）从购买决策中几大突出影响因素来看, 影响消 费者购买决策的突出影响因素主要有一次充电的行驶里 程、电池充电时间和使用寿命、良好的售后服务和汽车安 全装备, 这四个调查得分最高, 分别为 $4.34 、 4.33 、 4.20$ 、 4. 18 , 遥遥领先其他 18 项的均值得分。说明这四项是居民 购买新能源汽车最大的考量因素, 其中最重要的考量因素 就是一次充电的行驶路程和电池充电时间和使用寿命。消 费者比较普遍的新能源汽车购买意愿并没有转化为购买 行为, 主要是这四大因素在消费者心中拷上了顾虑的枷锁, 要想解决好新能源汽车叫好不叫座的窘境, 必须为消费者 除去这四块心病。

\section{2. 对策建议}

中央和各省市政府机构应当大力开展环保教育。推广 低碳消费、低碳生活，倡导市民的消费应当对环境负责。 我们在前面的调研当中, 我们的消费应当对环境负责这一 条项的得分达到 4.01 , 得分非常高, 说明我们市民对绿色 消费有很强的自我实践意识。购买新能源汽车是一种绿色 环保消费行为, 只有将这种 “购买新能源汽车能够切实的 保护我们的环境” 这一信息真实完整的传递给我们拥有较
高环保意识的居民, 才能使这些居民的绿色消费观念付诸 实际, 在购车时选择节能环保的新能源汽车。

另外, 政府要充分利用公众媒体和网络进行环保教育 和新能源汽车的宣传, 传播新能源汽车的基本知识, 营造 强大的社会與论氛围。在宣传新能源汽车的环保性过程中, 还应当注重新能源汽车安全性的宣传, 以促使居民将较高 的新能源汽车购买意向转化为实际购买行为。

企业应当积极投入开发新技术。在当今社会的大形势 下, 新能源汽车是汽车行业未来发展的不可逆转的大趋势。 中国企业在这个大形势下, 想在未来汽车行业拥有一席之 地, 就必须大力发展新技术, 努力自主创新和技术集成, 打破发达国家企业对核心技术的垄断, 尽快完成完整的产 业链。另外现阶段应当主要加强汽车电池技术的攻关, 提 高一次充电续航里程和电池使用寿命, 降低一次充电的充 电时间。解决好消费者心中最关心电池技术问题, 是赢得 他们信赖的最好的途径与方法。

另外, 新能源汽车是一种新产品, 在大家对新东西充 满期待和观望的情况下, 一定要狠抓质量检验关, 严格保 证新能源汽车的品质, 特别是其安全性能和操控性能。只 有在强有力的质量保证下，在社会大众当中营造一种安全、 可靠的产品氛围, 才能更好地吸引居民放心的来进行购买。

中国新能源汽车还面临着生产成本居高不下, 导致销 售价格过高的窘境。我们从调研中发现, 居民特别看中新 能源汽车的使用成本, 如果使用成本高于传统汽车, 居民 购买新能源汽车的意愿会大幅度降低。新能源汽车在使用 过程中的成本包括: 耗电成本, 维修成本, 保养成本和有 些混合动力车有耗油成本。如果要将较高的居民购买意愿 转化为实际购买行为, 新能源汽车生产企业就必须在成本 上下工夫, 而且一定要在降低居民的使用成本上下大功夫。

中央和各省市政府也可以适当的加大政策补贴力度, 加大补贴可以同时对企业进行补贴和对消费者进行补贴。 对企业进行补贴可以降低企业的生产成本, 可以降低新能 源汽车销售价格; 对消费者进行补贴, 可以降低消费者的 购置成本, 一定程度上提高消费者的购买能力和购买激励。 所以加大补贴额度, 有助于提高消费者购买新能源汽车的 积极性。

\section{参考文献}

[1] 唐葆君, 刘江鹏. 中国新能源汽车产业发展展望 [J]. 北京 理工大学学报, 2015, $17(2)$ : 1-6。

[2] 郑敬高, 冯森, 杨振东. 新能源汽车补贴政策的租金效应及 其应对 [J].科学与管理, 2014，(6)：71-76。

［3］马瑞婧. 《中国城市消费者绿色消费者行为的影响因素研 究》, 博士学位论文, 中南财经政法大学, 2006。

[4] 徐国虎, 许芳. 纯电动汽车购买决策的影响因素研究 $[\mathrm{J}]$. 中 国人口、资源与环境. 2010,20 (11)：91-95。

[5] 杨婕. 消费者对电动汽车购买意愿实证研究 [D]. 西南交通 大学, 2012。 
[6] Gallagher, K. S., Muehlegger, E. J., 2008. Giving green to get green: Incentives and consumer adoption of hybrid vehicle Technology [J]. Journal of Environmental Economics and Management, 2011, $61: 1-15$.

[7] David D. The impact of government incentives for hybrid-electric vehicles: Evidence from US states [J]. Energy Policy, 2009, 37:972-983.
[8] 何小洲, 雷裕倩. 相关群体对消费者购买行为的影响研究 [J]. 商场现代化, 2008 (19)。

[9] 李晶. 引导大众汽车消费的税收政策研究 $[J]$. 社会科学, 2009 (3)。

[10] 陈柳钦. 谈纯电动汽车产业发展的政策支持 $[\mathrm{J}]$. 汽车工业 研究. 2010 (6) :286-241。 